\title{
O IMAGINÁRIO SOCIAL DE DEMOCRACIA NO PROCESSO DE MUNICIPALIZAÇÃO DO ENSINO FUNDAMENTAL NO BRASIL (1985-1990)
}

DOI: http://dx.doi.org/10.1590/2236-3459/72148

\author{
Ariel Feldman' \\ 'Universidade Federal do Pará (UFPA), Cametá/PA, Brasil \\ Marina Feldman" \\ "Rutgers University, Nova Jérsei, Estados Unidos
}

\begin{abstract}
Resumo
Analisa-se o imaginário social de democracia da segunda metade da década de 1980, examinando de que forma ele influenciou a municipalização do Ensino Fundamental no Brasil. Objetiva-se, ainda, verificar como o municipalismo educacional em questão ajudou a construir o ideário segundo o qual instituições políticas localizadas contribuiriam para o aperfeiçoamento da democratização da sociedade. Foram analisados os debates veiculados nas instituições estruturantes da esfera pública, imprensa e parlamento. Concluiu-se que o imaginário de democracia que sustentou o municipalismo educacional durante a abertura política tinha grande capilaridade social, tendo sido decisivo para lançar as bases constitucionais de um amplo processo de reforma que só iria ser consolidado na década de 1990.

Palavras-chave: municipalização, ensino fundamental, imaginário social, democracia.
\end{abstract}

\section{EL IMAGINARIO SOCIAL DE DEMOCRACIA EN EL PROCESO DE MUNICIPALIZACIÓN DE LA EDUCACIÓN PRIMARIA EN BRASIL (1985-1990)}

\footnotetext{
Resumen

Se analiza el imaginario social de democracia en la segunda mitad de los años 1980, examinando de que manera influenció la municipalización de la Educación Primaria en Brasil. Aun se objetiva verificar como el municipalismo educacional ayudo a construir el ideario según lo cual las instituciones políticas ubicadas localmente contribuyen para el mejoramiento de la democratización de la sociedad. Se analizarán debates vehiculados en las instituciones estructurantes de la esfera publica, prensa y parlamento. Se concluye que el imaginario de democracia que sustento el municipalismo educacional durante la apertura política tenia gran capilaridad social, se mostrando decisivo para lanzar las bases constitucionales de un amplio proceso de reforma que sería consolidado en la década de 1990.

Palabras-clave: municipalización, educación primaria, imaginario social, democracia.
} 


\title{
THE SOCIAL IMAGINARY OF DEMOCRACY IN THE MUNICIPALIZATION OF ELEMENTARY EDUCATION PROCESS IN BRAZIL (1985-1990)
}

\begin{abstract}
The article analyzes the social imaginary of democracy in the second half of the 1980s, examining how it influenced the municipalization of the Elementary Education process in Brazil. It also aims at verifying how the advocacy of the municipalization helped building a comprehension that connects local political institutions to the enhancement of democracy. The debates on the structuring institutions of public sphere, the press and the parliament, were analyzed. The conclusion is that the imaginary of democracy that sustained the advocacy of the educational municipalization during the political aperture had a wide social capillarity, being decisive to insert such process in the constitutional propositions, allowing it to be consolidated in the following decade. Keywords: municipalization, elementary education, social imaginary, democracy.
\end{abstract}

\section{COMMENT L'IMAGINAIRE SOCIAL PEUT-IL INTERVENIR DANS UN CADRE DEMOCRATIQUE DANS LE PROCESSUS DE MUNICIPALISATION DE L'ECOLE PRIMAIRE AU BRESIL (1985-1990)}

\section{Résumé}

Nous étudions ici comment l'imaginaire social en matière de démocratie pour une période correspondant à la seconde moitié des années 1980-1990 a-t-il pu exercer une influence sur le principe de dé municipalisation de l'enseignement primaire au Brésil. Le but ici est de vérifier également comment le milieu de l'enseignement a pu favoriser l'idéologie selon laquelle les institutions politiques mises en place ont pu avoir un effet sur le processus de démocratisation de la société. Nous avons également analysé les différents débats qui ont traversé l'ensemble des institutions structurant la sphère publique, les médias et le Parlement. Enfin, nous avons pu conclure que l'imaginaire démocratique qui a maintenu le principe de municipalisation pendant la période d'ouverture politique avait pu diffuser socialement de façon ténue pendant la période d'ouverture de la politique éducative, fait qui a été décisif pour lancer les bases d'un plus large processus de réforme qui n'allait être consolidé qu'à partir seulement des années 1990.

Mots-clés: municipalisation, école primaire, imaginaire social, démocratie. 


\section{Introdução}

E ste artigo objetiva analisar o imaginário social (CASTORIADIS, 1982; MELLO, 1997) ${ }^{1}$ de democracia que sustentou o movimento em prol da municipalização do Ensino Fundamental (EF) no Brasil entre 1985 e 1990. Sugere-se que o imaginário social de democracia foi determinante para a aprovação das bases constitucionais que impulsionaram um processo que seria consolidado apenas na década seguinte, já sob a lógica da eficiência e gestão gerencial ${ }^{2}$. O movimento pela municipalização ganha força na década de 1980 , momento de efervescência social por conta da abertura política. Nesse contexto, a descentralização das políticas sociais é vista como condição para o aperfeiçoamento das instituições democráticas, pois aproximaria legisladores e gestores da população. Os cidadãos, em tal concepção, estariam próximos dos centros decisórios, podendo exercer participação política efetiva. (ARRETCHE, 2000; SOUZA, 2001; ABRUCIO, 1998).

Sustentada na ideia de aperfeiçoamento da democracia, a Constituição Federal de 1988 (CF/88) estabeleceu o federalismo como cláusula pétrea e elevou os municípios à condição de ente subnacional, formando um arranjo federativo bastante peculiar. No bojo dessas reformas federalistas, a constituição de 1998 estabeleceu que os entes federados atuariam em colaboração para organizar seus sistemas de ensino, sendo que "[...]os municípios atuarão prioritariamente no ensino fundamental e pré-escolar". (BRASIL, 1988).

Arretche (1996) observa a agregação de uma série de correntes políticas em torno da ideia de descentralização como meio de democratização das relações sociais. Casassus (1990, p. 12), analisando a América Latina, aponta para um "consenso utópico", que associava, de modo hegemônico, descentralização e democratização. Esse texto busca contribuir na compreensão desse fenômeno, analisando o imaginário social que sustentou o municipalismo educacional da segunda metade da década de 1980.

Que imagens acadêmicos, lideranças políticas, deputados constituintes e a sociedade civil projetavam do pleno funcionamento das instituições democráticas? Que importância esses agentes históricos conferiam à descentralização política municipalista para tal funcionamento? Donde provinha a imagem de que aproximar o povo dos centros decisórios aperfeiçoaria o funcionamento da democracia? Para responder a tais perguntas, segue-se a abordagem de Habermas (1984), que entende a imprensa e o parlamento como instituições estruturantes da esfera pública moderna. Assim, foi realizada análise de documentação jornalística - tanto a grande imprensa quanto a acadêmica - e parlamentar, isto é, os Anais da Assembleia Nacional Constituinte (1987-1988), notadamente os debates da Subcomissão da Educação, Cultura e Esportes (Sece). Também foram consideradas memórias escritas a posteriori por atores sociais relevantes no municipalismo dos anos 1980, bem como obras anteriores à década que foram apropriadas por esses atores sociais.

\footnotetext{
${ }_{1}^{1}$ Para Castoriadis (1982, p. 154) imaginário é "a capacidade [oriunda dos símbolos] elementar e irredutível de evocar uma imagem". Segundo o autor, as instituições não existem apenas para servir a interesses econômicos, mas também imaginários. Dessa forma, para "além da atividade consciente de institucionalização, as instituições encontraram sua fonte no imaginário social”. Segundo Mello (1997, p. 18), "o imaginário não desempenha o papel de uma superestrutura ideológica, de um epifenômeno, mas corresponde a uma dimensão constitutiva e reprodutiva das próprias relações sociais, isto é, ao processo pelo qual os grupos sociais se instituem como tais".

2 Durante toda a década de 1980 até 1996, os municípios ofereceram cerca de $30 \%$ das matrículas do EF no Brasil. Em 2003, ofereciam 51,87\%. (ARAÚJO, 2005, p. 43-47). Em 2014, já ofereciam 65,87\%. (CRUZ E MONTEIRO, 2016, p. 26).
} 
Assim, as principais fontes documentais que sustentam essa pesquisa se situam entre 1985, ano de fundação da União Nacional de Dirigentes Municipais da Educação (Undime), e 1990, quando finda a existência da Revista Educação Municipal (REM), principal veículo de divulgação do ideário municipalista da Undime. Nosso recorte cronológico está situado, portanto, dentro do contexto de abertura política e redemocratização, entre a posse do primeiro presidente civil após a ditadura civil-militar, eleito pelo colégio eleitoral, e a posse do primeiro presidente escolhido por eleições diretas.

Esse artigo, pretende, dessa forma, ser uma contribuição para a história política da educação brasileira, mais especificamente aquela que investiga a relação entre federalismo, políticas públicas, democracia e municipalização do ensino. (ANDRADE, 2013; ARAÚJO et al., 1988; VEIGA, 2011).

Primeiramente, apresenta-se periodização do municipalismo educacional brasileiro entre a ditadura militar e o fim do século $X X$, distinguido a municipalização democrática da neoliberal. Na sequência, é descrita a eclosão do municipalismo educacional dos anos 1980 e a heterogeneidade política desse movimento. Em seguida, analisa-se o imaginário social em torno da democracia norte-americana e sua influência no movimento municipalista brasileiro. Por fim, volta-se ao imaginário social municipalista da nova esquerda, constituído no processo de abertura política.

\section{Municipalização autoritária, democrática e neoliberal}

É necessário periodizar o processo de municipalização ${ }^{3}$ do EF no Brasil. Em um primeiro momento, na década de 1980, o imaginário social de democracia foi a base de sustentação do movimento municipalista. Em um segundo momento, iniciado em meados dos anos 1990 e concretizado com a Lei de Diretrizes e Bases da Educação Nacional (LDB) e o Fundo de Manutenção e Desenvolvimento do Ensino Fundamental e de Valorização do Magistério (Fundef), em 1996, a municipalização pautou-se na agenda neoliberal de reforma do Estado, induzida em partes por agências internacionais, que associavam a descentralização da gestão à redução do gasto público e à eficiência. (SOUZA; FARIA, 2014; CASASSUS, 2001; KRAWCZYK; VIEIRA, 2007).

Edwards Jr. e DeMattews (2014), em estudo comparativo das ondas descentralizadoras em diversos sistemas educacionais no pós Segunda Guerra, diferenciam a descentralização educacional neoliberal - cujo objetivo é delegar funções para esvaziar a responsabilidade do Estado, diminuir gastos e aumentar a oferta, promover o livre-mercado e adotar mecanismos de accountabilty - da descentralização democrática que tem como escopo a consolidação da democracia, a equidade de condições, a participação comunitária e o empoderamento local.

Entende-se que, no Brasil, esses dois movimentos - a descentralização democrática e a neoliberal - estiveram presentes desde os anos 1980, sendo ambos os discursos localizados na documentação analisada. Contudo, defende-se a tese de que, na segunda metade da década de 1980, o movimento municipalista brasileiro pautou-se predominantemente na imagem que vincula democracia a instituições localizadas. Ou seja,

\footnotetext{
${ }^{3}$ A municipalização da educação básica aqui é entendida como um processo extremamente amplo, que inclui tanto o debate público em torno dessa ideia, a adoção de dispositivos constitucionais e infraconstitucionais, a criação de redes municipais de ensino outrora inexistentes, bem como a transferência da rede estadual para a alçada do município.
} 
nesse quadrante histórico, o discurso em prol da eficiência esteve subordinado às aspirações democráticas de um país que almejava sair de uma ditatura de duas décadas.

Como bem definiu em memórias uma importante atriz social da época, nos anos oitenta havia uma "fúria por democracia, por liberdade". (RIBEIRO; SILVA, 2014, p. 220). ${ }^{4}$ Assim, tal qual sugeriu Nobre (2013, p. 29), "muitas vezes considerada como período do ajuste estrutural à nova etapa do capitalismo mundial, a década de 1980 foi, na verdade [no Brasil], a do adiamento do ajuste mediante descontrole inflacionário e fechamento da economia". A democratização da sociedade, portanto, subordinava outras pautas, que, mesmo presentes no debate político, como o ajuste à nova etapa do capitalismo mundial, tornavam-se secundários se relacionados ao tema da redemocratização.

Existe uma série de estudos, alguns citados acima, analisando a legislação dos anos 1990 que, em conjunto com políticas nacionais indutoras a partir do financiamento público, sustentou a municipalização sob a lógica neoliberal. (MARTINS, 2009). Existem, também, diversas análises sobre a aplicação dessa legislação infraconstitucional através de convênios entre estados e municípios, que contaram com pouca ou nenhuma participação popular. (GUTIERRES, 2012; MARTINS, 2003; ALBUQUERQUE, 2005). Este estudo, porém, pretende contribuir para o entendimento do momento em que foram lançadas as bases constitucionais de tal processo.

É preciso ressaltar, por fim, que a ditadura civil-militar (1964-1985) já havia realizado tentativas de transferir o ensino de $1^{\circ}$ grau para o município, a partir da LDB de 1971. Sem ignorar tal municipalismo, que já se vinculava às exigências de agências financeiras internacionais e teve significativa importância para pequenos e pobres municípios da região Norte e Nordeste, ele não será escopo dessa análise por ser de natureza distinta do movimento político e social surgido nos anos 1980. A ideia de democratização da educação através da municipalização não era o escopo do discurso dos tecnocratas que sustentaram tal governo. (MELLO, 1988; ROSAR, 1995; GUIMARÃES, 1995).

\section{A capilaridade social do municipalismo educacional dos anos 1980}

Em 1985, o ministro da educação Marco Maciel, do Partido da Frente Liberal (PFL), declara apoio à municipalização da educação básica. (JORNAL DO BRASIL, n. 9, 1985, p. 6). No mesmo ano, dirigentes reunidos no 1a Fórum Nacional dos Dirigentes Municipais de Educação, redigem e aprovam o estatuto da União Nacional de Dirigentes Municipais da Educação (Undime) (JUNGMANN, 1988), principal articuladora do movimento em defesa da municipalização do EF no Brasil, com pensamento majoritariamente de base marxista.

A aliança da Undime com o Ministério da Educação (MEC), controlado pelo PFL, tem sido interpretada como estratégia política. A Undime precisava consolidar a municipalização como pauta na Assembleia Nacional Constituinte (ANC). O PFL, por sua vez, viu na aliança com as prefeituras uma base de sustentação. (ROMÃO, 1998; AZEVEDO, 2001). Tal vertente explicativa é relevante, porém insuficiente. Mais além, entende-se que o imaginário que associava democracia a instituições altamente localizadas possuía ampla capilaridade social, sendo significativa a heterogeneidade dos atores sociais

\footnotetext{
${ }^{4}$ A expressão foi usada por Lia Faria, a qual trabalhou com Darcy Ribeiro e Maria Yedda Linhares na implantação dos Cieps entre 1983 e 1987, experiência histórica que será abordada no decorrer desse artigo.
} 
que lideraram o movimento municipalista.

Entre 1988 e 1990 circulou a Revista Educação Municipal (REM), financiada pela Undime e com compromisso declarado "de defesa da escola pública e de uma educação democrática e popular". (REM, n. 1, 1988, p. 3). Entre os autores veiculados estão José Eustáquio Romão, Ladislau Dowbor e Paulo Freire, evidenciando que núcleo duro do municipalismo educacional era vinculado ao pensamento da eclética esquerda do período. Freire (1988) e Dowbor (1988), cujo artigo será analisado adiante, participaram da gestão municipal do Partido dos Trabalhadores (PT) na prefeitura de São Paulo. Romão (1988), Secretário Municipal de Educação de Juiz de Fora pelo Partido do Movimento Democrático Brasileiro (PMDB) e Secretário Geral da Undime, realiza análise que vincula a luta de classes à abertura democrática no Brasil, identificando o município dentro desse processo histórico como local privilegiado de participação popular.

Assim, o imaginário de democracia aparece vinculado a experiências históricas concretas, forjando-se na realidade e ajudando a forjá-la. (MELLO, 1997; BACZKO, 1985; ESPIG, 2004). As gestões municipais do PT a partir de 1989 (KOWARICK E SINGER, 1993; FRANCO, 2014), foram elementos construtores do imaginário social aqui analisado, assim como a gestão de Maria Yedda Linhares na Secretaria Municipal de Educação do Rio de Janeiro (1983-1987) pelo Partido Democrático Trabalhista (PDT). Linhares, em parceria com o vice-governador Darcy Ribeiro e o governador Leonel Brizola, coordenou a construção de centenas de Centros Integrados de Educação Pública (Cieps), unidades escolares projetadas por Oscar Niemeyer. Trata-se de reforma considerada utópica por Faria (1992), tendo ampla visibilidade nacional (MIGNOT, 2001) e contribuindo com o imaginário social aqui investigado. Linhares, que se situa no eclético campo da esquerda do período, vinculada ao trabalhismo histórico de Vargas e Goulart, foi signatária da citada carta enviada ao ministro da educação e, segundo o Jornal do Brasil (n. 13, 1985, p. 17), após encontro com Maciel, "pregou a descentralização do $1^{\circ}$ grau estabelecida pela 5693/71 [LDB], mas só cumprida por um município do país: o Rio de Janeiro, que este ano reservou para a educação $42 \%$ do orçamento municipal".

Mas nem só do pensamento e das experiências de esquerda alimentou-se o municipalismo educacional. Guiomar Namo de Mello, Secretaria de Educação de São Paulo na gestão Mário Covas (PMDB), foi signatária da carta entregue ao Ministro da Educação. Mello não pode ser caracterizada como uma municipalista strictu sensu, já que o artigo que escreveu para a REM é um dos mais críticos em relação à municipalização. Mello (1988, p. 58) entende que o município "não é a priori a instância mais democrática só por ser mais próxima [do cidadão]". Contudo, Mello foi, na área da educação, uma das principais cabeças pensantes de seu grupo político, isto é, dos fundadores do Partido da Social Democracia Brasileira (PSDB), e ajudou, de alguma forma, a forjar o municipalismo educacional. Como veremos, outra figura relevante na aprovação do texto constitucional de teor municipalista, e que não pode ser definida como de esquerda, foi João Calmon, célebre pela Emenda Calmon, de 1983, que vinculou receitas orçamentárias à educação.

Vale destacar que nos estados do Rio de Janeiro, São Paulo e Minas Gerais foram implantados programas de municipalização depois do advento da carta magna de 1988 , todos durante gestões do PMDB. (NEVES, 1992). No Rio de Janeiro, por exemplo, foi interrompida a política educacional brizolista do PDT. Contudo, o discurso municipalista foi apropriado pelo grupo rival, que implantou, a partir de 1987, controvertido programa de 
municipalização. Tais programas sofreram diversas resistências (ARELARO, 1989), sobretudo sindicais, tendo problemas técnicos na implantação. Entretanto, vale destacar que, a despeito da presença de concepção técnica de eficiência, os programas se sustentavam na ideia de democratização da educação,

Demonstrada a heterogeneidade dos atores sociais que lideraram e se apropriaram do movimento municipalista, passemos ao entendimento do imaginário social de democracia que o sustentou. Sendo um contexto histórico ainda influenciado pela polarização caraterística do mundo pós Segunda Guerra, a construção de um imaginário social que penetrasse tanto no pensamento de esquerda como no liberal formou importante base de sustentação para o sucesso da onda municipalista.

\section{O imaginário social da democracia norte-americana}

Tendo em vista a posição política majoritária da Undime, vinculada à nova esquerda, associações entre democracia e EUA poderiam ser mal interpretadas. A análise se complexifica, sendo necessário buscar o "fio e os rastros" (GINZBURG, 2007) através de uma digressão histórica. $O$ primeiro pressuposto que orienta a análise é de que $O$ imaginário da democracia e federalismo norte-americanos exerceu, desde o século $X I X$, importância nas discussões políticas no Brasil.

Presenciou-se um embate tipicamente americano ao longo do processo de formação dos Estados nacionais que surgiram no Novo Mundo a partir do final do século XVIII: entre federalismo e unitarismo. Os exemplos são diversos (SLEMIAN, 2005), por se tratarem de Estados com grande dimensão territorial e uma série de regiões, mais ou menos definidas durante a colonização, tendo habitantes portadores de complexas noções de identidade e pertencimento político.

No Brasil, esse embate teve larga duração. Durante o século XIX, houve tentativas de construção de Estado unitário e de Estado federativo, no qual o centro (Rio de Janeiro) dividiria competências legislativas com as províncias, conferindo a estas autonomia para tributar e administrar receitas. Até hoje a historiografia trava um embate para definir a natureza do Estado imperial brasileiro, se unitário ou federativo. (MATTOS, 1990; CARVALHO 2005; DOLHNIKOF, 2005). O ensino de primeiras letras, nesse contexto, ficou sob responsabilidade das províncias, sendo que governo central administrava o ensino superior ${ }^{5}$.

O imaginário do sistema político norte-americano sempre exerceu influência nas discussões políticas nacionais, sobretudo quando se discutia democracia e federalismo. $\mathrm{Na}$ década de 1830, jornalistas brasileiros apropriaram-se da obra de Alexis de Tocqueville de 1834, Democracia na América, que influenciou a maneira como o mundo enxergou os EUA no século XIX. (TOCQUEVILLE, 1998). Tal apropriação foi usada, por exemplo, para diminuir o número de instituições eletivas no Brasil, a partir da visão de que povo brasileiro não estaria preparado para a democracia. (FELDMAN, 2006). Voltaremos ao pensamento tocquevilliano adiante, mas tal digressão permite perceber que imagens dos EUA

\footnotetext{
${ }^{5}$ Aqui advoga-se ser equivocado atribuir as origens do municipalismo na educação à lei de $1^{\circ}$ de outubro de 1828, que regulamentou o funcionamento das Câmaras Municipais. Entende-se tal formulação como problemática, já que a partir de 1834, com o Ato Adicional, as Câmaras Municipais passam a ser subordinadas às Assembleias Provinciais. O sistema educacional imperial foi, portanto, montado e gerido pelas províncias, sendo as Câmaras Municipais agentes executores. (DOLHNIKOF, 2005).
} 
exerceram influência nas discussões políticas travadas no Brasil, sobretudo em torno da construção de instituições democráticas e do federalismo. Isso fica mais evidente na Primeira República (1889-1930), quando o país passou a ser denominado de Estados Unidos do Brasil. (LOVE, 1993).

Nosso segundo pressuposto histórico é que o movimento em prol da municipalização do EF no Brasil inspirou-se, desde a década de 1940, no sistema educacional norte-americano. Observam-se dois momentos de efervescência nas discussões sobre educação pública no Brasil, com a municipalização do EF sendo pauta central em ambos. O primeiro foi o período democrático após o fim do Estado Novo, em 1945, durando até o golpe de 1964. O segundo remete ao recorte dessa pesquisa. Tais momentos carregam similaridades, pois buscava-se superar um regime autoritário e centralizador. (ARAÚJO, 2005).

O movimento em prol da municipalização, portanto, se estabelece nos anos 1940, retomando debates esboçados na década de 1920 (ARAÚJO et al., 1988) e também pelo movimento dos Pioneiros em 1932, mas silenciados durante o Estado Novo a partir 1937. Nesse cenário, se faz necessária retomada do pensamento do principal formulador do movimento municipalista: Anísio Teixeira.

Teixeira foi um admirador da cultura escolar e da sociedade norte-americana. (WARDE, 2006). Durante sua primeira experiência como gestor educacional, impressionase com a leitura da obra Métodos Americanos de Educação (BUYSE, 1927), solicitando à Imprensa Oficial do Estado da Bahia sua imediata tradução. Logo em seguida, após realizar duas viagens aos EUA e publicar duas obras refletindo sobre o que observou, afirmou que "a tradição americana, o que há de ficar com a lição desse povo, como sua contribuição característica para humanidade, não é puramente o industrialismo moderno, mas o espírito de sua democracia". (TEIXEIRA, s. d. [1934?], s. p.). Teixeira (1928, p. 139) acreditava, que "a escola secundária aqui [nos EUA] está penetrada da mesma ideia de educação popular que reveste totalmente a ideia de educação primária”. Segundo Cardoso (2007, p. 104), "ao enaltecer e enobrecer o 'outro', Anísio opera um distanciamento, apontando [...] uma fenda entre o modelo educacional dos Estados Unidos e do Brasil", afirmando as "qualidades do 'outro' e os defeitos do 'nós'".

Seu pensamento municipalista, incubado desde as primeiras viagens aos EUA, é sistematizado de forma mais amadurecida em tese apresentada no Congresso Nacional de Municipalidades, em 1957. (TEIXEIRA, 1989). O sistema educacional sugerido no documento contém semelhanças com o sistema distrital norte-americano, admirado desde sua primeira viagem, quando descreveu distritos educacionais urbanos e rurais dos EUA. (TEIXEIRA, 1928). Ele concluía sua tese de 1957 dessa forma:

Dizem que não temos espírito de comunidade. Como poderíamos tê-lo, se as instituições, que formam esse espírito, são [...] ligadas aos poderes centrais e distantes [...], e em rigor alienadas do espírito local, do gênio local e do interesse local? [...] A municipalização do ensino primário não é uma reforma administrativa nem pedagógica, embora seja tudo isso; é, principalmente, uma reforma política e o reconhecimento definitivo da maioridade de nossas comunidades municipais. (TEIXEIRA, 1988, p. 136).

Teixeira foi leitor e tradutor de Tocqueville (WARDE, 2007) e, na tese municipalista de 1957, inverte a leitura realizada por jornalistas brasileiros nos anos 1830 . Se, para os 
periodistas oitocentistas o povo Brasileiro não era propenso a um excesso de instituições eletivas, para o educador baiano era preciso cultivar hábitos democráticos criando instituições que permitissem a transformação nos costumes do povo. Para Teixeira (1988, p. 136), "confiar no Brasil é confiar nos Municípios, onde se está a processar a mais nova revolução democrática da vida brasileira". Teixeira ressignifica Tocqueville, entendendo ser preciso modificar as instituições para que o espírito democrático fosse localmente cultivado.

O educador baiano, falecido em 1971, foi amplamente lido na década de 1980. O pensamento de Teixeira é onipresente no movimento municipalista. No primeiro número da $R E M$, de junho de 1988, é publicado verbete com a vida e a obra de Teixeira. No quinto número da $R E M$ é republicada a tese apresentada em 1957, tendo o editor da revista afirmado se tratar de uma contribuição ainda atual. (TEIXEIRA, 1989, p. 121). Em outra edição, é publicado perfil intitulado Mestre Anísio, escrito por Darcy Ribeiro (1988), que se afirmava influenciado por Teixeira.

[...] esta questão só foi posta para mim porque Anísio a colocou. [...] Refiro-me à ideia de que a educação deva ser comunitária. Ele acreditava que era preciso conceder ao governo estadual, e, menos que ao estadual, ao municipal, o poder e a obrigação de educar, para que um dia a própria comunidade tomasse em suas mãos a educação de seus membros, porque só assim a instrução pública encontraria uma base na realidade para se firmar e difundir-se a todos. (RIBEIRO, 1988, p. 60).

É preciso indicar que a associação entre participação comunitária local e desenvolvimento da democracia parece remeter a uma imagem dos distritos escolares estadunidenses. Entre as nações que adotam o sistema federativo, a maioria não possui jurisdições educacionais altamente localizadas, em geral sendo divididas as competências educacionais entre estados e governo federal. Além do Brasil, apenas EUA e Canadá possuem organismos educacionais locais responsáveis pela educação pública. (MORDUCHOWICZ; ARANGO, 2010). Nesses países, os organismos locais têm origem no processo de colonização, feito por seitas protestantes que tradicionalmente estabeleciam escolas comunitárias. (KARNAL, 2010). Já no Brasil, as secretarias municipais de educação autônomas têm origem jurídica na CF/88. Nos EUA, ainda que a educação fundamental seja de responsabilidade dos estados, a maioria deles delegou liberdade de decisão, em diferentes graus, a jurisdições educacionais altamente localizadas. Os distritos educacionais, historicamente, tiveram autonomia do governo federal, tanto fiscal como administrativa. Originalmente, inclusive, estabeleciam e recolhiam impostos para a educação básica de forma independente. (PINTO, 2005; ARRETCHE 2002; FISCHEL, 2009).

Voltemos, contudo, ao municipalismo da década de 1980, verificando imagens que associam democratização à participação comunitária nos moldes norte-americanos. Em 1989, no jornal Estado de São Paulo, o ex-presidente do Conselho Federal de Educação, Paulo Nathanael, afirma que sempre foi e continuava a ser um adepto da municipalização do EF. "Aprendi essa lição com o mestre Anísio Teixeira e nunca mais dela me apartei". Na sequência, cita um trecho da já citada tese de Teixeira de 1957: "A administração local concorrerá para tornar possível essa integração, passando a escola a ser a instituição fundamental da comunidade, servindo-se e dela se servindo para a vitalidade e a riqueza dos seus processos educativos". (NATHANAEL, 1989, p. 52). Em artigo publicado no Jornal 
do Brasil, em 1988, o historiador José Murilo de Carvalho, que fizera seu doutorado na Stanford University, reflete sobre a relação entre centralização, descentralização e democracia, desde o século XIX aos tempos presentes.

\begin{abstract}
A justificativa [para a centralização do Estado no Brasil imperial] foi dada pelo principal teórico do regresso ${ }^{6}$, o visconde do Uruguai; o self-government é o governo ideal mas, nas circunstâncias brasileiras, dadas nossas características culturais, as instituições do self-government provocam resultados opostos aos que tinham os Estados Unidos. Isto é, a descentralização política colocava o cidadão à mercê dos régulos locais, mais arbitrários do que as autoridades do governo central. (CARVALHO, 1988, p. 40, grifos do original).
\end{abstract}

Interessante notar que as ideias do Visconde do Uruguai, sintetizadas por Carvalho, reiteravam a ideia de que os brasileiros não estariam, no século XIX, aptos para a democracia. Depois de realizar uma análise histórica detalhada, Carvalho faz sua ponderação sobre o momento pelo qual passava o país nos anos 1980, num exercício de consciência histórica (RÜSEN, 2012), isto é, pensar o futuro tendo o passado como parâmetro:

\begin{abstract}
Mas é preciso atenção. O novo debate não pode ser colocado como antigamente. Seria um retrocesso, por exemplo, colocá-lo em termos puramente federalistas [...] Esta é a velha noção oligárquica que não contém o ingrediente democrático. A democratização do Estado pela descentralização pode incluir um reforço dos governos estaduais em relação ao governo central, mas deverá, principalmente, significar um reforço dos governos municipais em relação aos governos estaduais. A municipalização foi sempre evitada pelos federalistas brasileiros, do Ato Adicional de 1834 ao movimento dos governadores de hoje. Mas se há algum sentido na ideia de self-government ele está na vida municipal onde o poder pode ser mais facilmente controlado pelos contribuintes e pelos votantes. Federalismo sem municipalismo seria um anacronismo. (CARVALHO, 1988, p. 40, grifo do original).
\end{abstract}

Carvalho, sintomaticamente valendo-se do termo self-government em negrito, reitera a ideia arraigada no imaginário social dos anos oitenta: instituições altamente localizadas cumpririam função pedagógica de democratizar a sociedade. Carvalho usa o termo "contribuinte", o que remete à instituição do distrito escolar norte-americano, em que a taxação é feita diretamente entre habitante e gestor.

A força do imaginário de democracia norte-americano, que atrela a participação comunitária ao aperfeiçoamento da democracia, ajuda a explicar um paradoxo ocorrido na Assembleia Constituinte entre 1987 e 1988. Durante os trabalhos da Sece, especialistas, representantes de associações de pesquisa em educação e deputados alertaram reiteradamente para os perigos da municipalização do EF, argumentando que a estrutura fiscal do Brasil era centralizada e chamando atenção para ausência de mão-de-obra qualificada nos municípios para organizar a gestão educacional. Representando a Associação Nacional de Educação (Ande), a professora Elba Siqueira de Sá sintetizou a crítica que teve bastante repercussão durante os trabalhos da Sece.

Para dirimir essa dívida nacional, [...] é preciso o esforço nacional. E nesse sentido, qualquer divisão de atribuições [...] é precária, no sentido de que não podemos jogar para uma instância só o cumprimento dessa obrigação do Estado brasileiro, com

\footnotetext{
${ }^{6}$ Carvalho $(1996$; 2007) é autor de obras paradigmáticas da historiografia política do Brasil Imperial, nas quais reflete sobre o regresso conservador, movimento político iniciado na década de 1830.
} 
relação ao serviço básico de educação fundamental. [...] Em termos de País, eu acho que não é só uma questão de Reforma Tributária; a maioria dos nossos Municípios não têm recursos humanos, não têm infraestrutura. (BRASIL,1987, p. 46-47).

Apesar dessa argumentação crítica em relação à municipalização do EF no Brasil (ARAÚJO, 2010), marcante na Sece, o texto constitucional aprovado induzia a transferência dessa etapa para o município, estabelecendo que "atuarão prioritariamente no EF e préescolar". (BRASIL, 1988). Como explicar tal paradoxo? A atuação de Calmon, relator da Sece, ajuda a responder tal questão, com indícios de que o imaginário da democracia norteamericana teve relevância em sua atuação.

Desde 1962 como parlamentar, Calmon, historicamente ligado ao partido de sustentação da ditadura, a Aliança Renovadora Nacional (Arena), teve atuação aparentemente decisiva para que o texto aprovado na Sece sobrevivesse na Comissão Temática, na Comissão de Sistematização e fosse aprovado no plenário da Constituinte sem grandes alterações. (CALMON, 1991). Ressalte-se que, tanto o primeiro relatório da Sece como o substitutivo, isto é, dois textos redigidos por Calmon, eram mais municipalistas que o documento final. Dois parágrafos, redigidos por Calmon, que foram suprimidos por conta da oposição da maioria dos constituintes da Sece, estabeleciam que a passagem da responsabilidade dos estados aos municípios aconteceria sempre que houvessem condições técnicas e financeiras e que os municípios só poderiam atuar em outras etapas quando as necessidades relativas ao EF estivessem atendidas de modo satisfatório. (BRASIL, 1987, p. 473-474, 512 e 541-543).

Quando foram lidos os parágrafos acima mencionados no texto do substitutivo, que já haviam recebido duras críticas na discussão do primeiro relatório, o constituinte Octávio Elísio reclamou da insistência de Calmon:

\footnotetext{
Portanto, se há da parte de V. Ex.. a , que tenho certeza que sim, uma ideia de que a democratização passará por decisões mais próximas da comunidade, me parece extremamente perigoso que esta Subcomissão adote, sob dispositivo constitucional, o compromisso com a municipalização do ensino. (BRASIL, 1987, p. 518).
}

A definição que Octávio Elísio fez de Calmon não poderia ser mais precisa: um crente na "ideia de que a democratização passará por decisões mais próximas da comunidade". Calmon, para redigir o relatório da Sece, teve assessoria de Cândido Alberto da Costa Gomes, então pesquisador da Universidade de Brasília e assessor legislativo do Senado. (CALMON, 1991, p. 37). Gomes havia realizado doutorado na University of California e seu mestrado versava sobre relacionamento escola-comunidade, indicando como fator de sucesso dessa relação o grau de vida comunitária do entorno. (GOMES, 1980). É difícil medir a influência de Gomes no relatório, contudo, indícios apontam para emulação, por Calmon, do imaginário da democracia norte-americano.

O relatório original de Calmon teve outros dois parágrafos suprimidos no texto final. Segundo essa proposta suprimida, municípios com mais de 50.000 habitantes teriam de organizar Conselhos de Educação cujos membros seriam eleitos ao mesmo tempo que os parlamentares municipais. (BRASIL, 1987). Trata-se de proposta semelhante à de diversos distritos escolares estadunidenses, governados por um conselho escolar (School Board), 
na maioria das vezes eleitos pela comunidade. (PINTO, 2005; FISCHEL, 2009). ${ }^{7}$ No final dos trabalhos da Sece, Calmon se surpreende com a supressão de tal proposta e declara que a ideia de conselhos municipais de educação não partiu de sua imaginação, "mas sim da experiência de numerosos países que os possuem com extraordinário êxito, porque permitem a fiscalização da atuação de professores, de diretores de escolas nos três níveis". (BRASIL, 1987, p. 568). A referência à numerosos países parece uma tentativa de ressignificar a emulação do modelo norte-americano.

Analisado o potencial de interferência do imaginário da democracia norteamericana, que atrela a participação comunitária ao aperfeiçoamento democrático, na luta política do municipalismo educacional dos anos 1980, passemos a analisar o imaginário da nova esquerda.

\section{O imaginário social de democracia da nova esquerda}

Analisando os movimentos sociais e a participação política entre as décadas de 1970 e 1980, Doimo (1995, p. 75) afirma que "nunca como neste período as ideias de povo e de participação popular ganharam tanta significação positiva no pensamento sociológico da esquerda". No contexto em que o ecumenismo católico revaloriza o trabalho de base comunitária, o povo é resgatado enquanto sujeito histórico, em interação entre setores da Igreja Católica, da intelectualidade e com o que é chamado de nova esquerda. Busca-se resgatar a capacidade ativa da população na vida política.

Já em relação ao pensamento educacional brasileiro da década de 1980, pode-se indicar um consenso teórico-metodológico em torno de um marxismo eclético, articulado em redes de sociabilidade urdidas nos programas de pós-graduação e em eventos acadêmicos-militantes, organizados sobretudo na região sudeste. (SANTOS, 2010). Nesse contexto, a base marxista do municipalismo educacional, que era o núcleo duro do movimento, vinculou a ideia de participação popular à participação comunitária em pequena escala, a única capaz de promover a auto-gestão do povo pelo povo. Se fosse possível realizar uma síntese deste pensamento complexo e multifacetado, essa síntese seria a crença na sociedade civil como um contraponto ao Estado centralizador e antipopular e a noção de que as conquistas populares se processam através de movimentos sociais de base comunitária.

Na última seção do primeiro número da $R E M$, refletindo sobre a atuação da Undime na constituinte, o redator anônimo entendia a descentralização da década de 1980 como uma conquista popular, diferente da "nossa triste história 'central-unitarista'”, pois por

[...] ingenuidade, ou, no limite, por má fé, fala-se muito na descentralização resultante da iniciativa do governo, como uma espécie de favor decorrente da boa vontade de governantes iluminados. [...] Não é demais repetir que a transição democrática foi oportunizada pelas conquistas populares. (REM, n. 1, 1988, p. 114116).

Para ele, no bojo da mobilização geral, nasceu em 1986 o movimento dos dirigentes municipais de educação, diferenciando a descentralização concedida da linha de atuação

\footnotetext{
7 Historicamente, existiram distritos escolares nos Estados Unidos de diversos tamanhos, sendo comum distritos com menos de 50 mil habitantes. Atualmente, há uma tendência de fusão de distritos, com a justificativa de que unidades educacionais maiores são geridas de modo mais eficaz. (HOWLEY et al., 2011).
} 
da Undime, autêntica manifestação da vontade popular. Sugeria, por fim, findado o processo constituinte, realizar Congresso Nacional da Educação Básica, que abriria às comunidades a participação na formulação de políticas públicas, incorporando a experiência popular e trabalhando pela municipalização da educação básica.

No segundo número da revista, intitulado "Escola pública popular", o editorial de Waldyr Amaral Bedê (1988, p. 3), então presidente da Undime, afirma que a edição pretendia contribuir com a "construção de uma escola com outro caráter social, que definimos como popular". Esta escola não seria uma extensão da escola pública burguesa, mas "um modelo de instituição de ensino participativa".

Moacir Gadotti, figura de destaque no municipalismo educacional e editor da REM, defendia a "escola pública estatal mas com controle social, tendendo à autogestão escolar". Em alusão às ideias de Gramsci, defende "uma escola pública criada e mantida pelo Estado, mas sob o controle da sociedade civil [...], uma escola autogovernada; em outras palavras: uma escola única popular". Gadotti (1988, p. 9), entendia que "a escola pública, popular e democrática, só pode ser uma conquista da população organizada, jamais uma doação do Estado capitalista", sendo "o problema da escola pública [...], em grande parte, o problema de tornar popular o 'público', de elevar o popular ao nacional".

Gadotti esteve presente na Sece, junto com Paulo Freire, defendendo a eleição, nos municípios, de Conselhos Populares de Educação. (BRASIL, 1987, p. 482). Ele entendia que um programa de educação popular deve envolver os pais e a comunidade e "incluir formas de participação como, por exemplo, os Conselhos de Escola, com caráter deliberativo, e os Conselhos Municipais de Educação", pois só assim será possível uma escola "autônoma, isto é, sob a hegemonia da população". (GADOTTI, 1988, p. 8).

Reinaldo Matias Fleuri (1988, p. 22-24), professor da Universidade Federal de Uberlândia, fazia contraponto, influenciado pelas ideias de Althusser e Gramsci, teóricos marxistas centrais no pensamento educacional brasileiro dos anos 1980. (YAMAMOTO, 1997). De um lado, uma escola patrocinada pelo Estado para "consolidar o controle ideológico sobre as classes subalternas". De outro, a educação popular, na qual "a direção permanece sob o controle dos movimentos gestados pelas classes populares".

Carlos Pereira de Carvalho e Silva (1988, p. 31), então presidente da Fundação de Assistência ao Estudante (FAE), entendia que "a revitalização do poder decisório local, expresso no seu núcleo principal - o município - passa necessariamente pela abertura de um canal de participação popular [...]". No seu entendimento, "o município deve ser entendido como um ambiente preferencial de implementação de políticas públicas[...]".

Os exemplos são diversos e apontam para um imaginário social de democracia do municipalismo educacional de esquerda que vincula participação popular à participação comunitária em pequena escala. Enaltece-se a auto-gestão do povo, e a crença na sociedade civil como contraponto ao Estado centralizador e antipopular, defendendo que conquistas populares se processam através de movimentos sociais de base comunitária. É preciso, contudo, analisar as bases teóricas que alimentaram esse municipalismo. 0 pensamento e a atuação de Florestan Fernandes auxiliam nessa empreitada.

Fernandes foi constituinte pelo PT e membro da Sece. Ele chegou a alertar sobre os perigos dos dispositivos municipalistas do relatório de João Calmon. (BRASIL, 1987, p. 542). Isto se deve, muito provavelmente, aos diversos pareceres contrários emitidos por especialistas nas plenárias da Sece. Contudo, Fernandes não se opôs ao texto final 
aprovado e que forneceu as bases constitucionais para que os municípios atuassem prioritariamente no EF e na Educação Infantil. No projeto que apresentou à subcomissão, publicado na $R E M$, Fernandes sugeria um artigo constitucional que instituía que "o ensino básico obrigatório é prioritário sobre os demais". (REM, n. 1, 1988, p. 89). Na Sece, afirmou que "o ensino de $1^{\circ}$ grau é o ensino que está exigindo uma atenção imediata, radical". (BRASIL, 1987, p. 112). Como explicar que a etapa considerada prioritária pudesse ficar sob responsabilidade de um ente federado tributariamente frágil?

Para Avelino (2012, p. 20), as ideias de Florestan "refletem o contexto da época de afirmação da autonomia dos movimentos sociais em relação ao Estado e da possibilidade de atuação paralela entre ambos". Como observou Martorano (2009, p. 15), se o marxismo não dispõe de uma teoria democrática, a vertente teórica que relaciona diretamente democracia e socialismo é o conselhismo. Não é por acaso que Fernandes se vincula ao pensamento de Rosa de Luxemburgo (1991 [1923], 1971 [1918]), que fomentou tal vertente marxista e realizou aguda crítica à burocratização centralista levada a cabo na União Soviética. Tampouco é fortuita a associação do sociólogo paulistano ao pensamento de Gramsci (1976 [1919]), que teorizou sobre a experiência dos conselhos de fábrica no norte da Itália. Nas palavras de Fernandes (2000[1989], p. 11), "igualdade sem liberdade não corresponde ao ideário e à utopia do socialismo, tão bem encarnados por Rosa de Luxemburgo e Antonio Gramsci", pois ambos "acreditavam nos sovietes - ou conselhos e promoviam a exaltação de sua autonomia contra os desvios burocráticos [...]". Fernandes (1990, p. 13) entendia caber "ao conselho popular uma atividade permanente e paralela na elaboração de diretrizes, ações e decisões dotadas de legitimidade própria consagrada pelo direito objetivo da vox populi".

O conselhismo e o pensamento de Gramsci ajudam a entender, do ponto de vista teórico, a simpatia de Florestan Fernandes e de parte da esquerda brasileira da época, aos movimentos sociais de bases comunitárias, entendidos como indispensáveis para a transição democrática de viés socialista. Fleuri (1988, p. 23), por exemplo, entendia, como paradigma de uma educação popular, as escolas criadas e dirigidas por organizações socialistas e anarquistas de trabalhadores da década de vinte na Itália. Contudo, apesar de ser imprescindível compreender os teóricos marxistas que pensaram a relação entre democracia e socialismo, pois nessa teoria residem aspectos primordiais do imaginário social analisado, é preciso ter em mente a autonomia e a inventividade do movimento aqui analisado. As apropriações não são cópias, mas ressignificações. Em se tratando do imaginário social, um significante novo reinventa o antigo significado. (ESPIG, 2004).

O imaginário social é uma força capaz de promover transformações históricas e não está desconectado da realidade material, ou seja, das experiências concretas vivenciadas. Segundo Santos e Avritzer (2002), diversas experiências gestadas nesse quadrante histórico, em especial na América Latina e nos países pós-coloniais, constituíram uma gramática política alternativa ao cânone democrático estabelecido no hemisfério norte. Santos (2002), por exemplo, entende que a experiência petista na prefeitura de Porto Alegre, com a implantação do orçamento participativo, constitui alternativa para questionar a democracia representativa formal, através da instituição de mecanismos de participação direta. Dessa forma, o imaginário social analisado deve ser pensado atrelado ao ativismo social vivenciado nas Comunidade Eclesiais de Base, ao modo petista de governar centrado no orçamento participativo e à efervescência de movimentos sociais que surgiram 
no contexto da redemocratização. (TEIXEIRA, 2002; SANTOS, 2002; DOIMO, 1995).

Por fim, é interessante observar que, apesar de distinto do imaginário social de democracia analisado no subtítulo anterior, a esquerda brasileira municipalista da década de 1980 também tinha um projeto pedagogizante. Luxemburgo entendia que o aprendizado operário se dava durante o processo revolucionário. Gramsci (1976, p. 337), de forma semelhante, entendia que apenas com trabalho de "esclarecimento, de persuasão e de educação recíproca, nascerá a ação concreta de construção".

Celso Daniel, candidato derrotado a prefeito de Santo André pelo PT em 1982, entendia que "a descentralização da gestão local pode ser condição para o fortalecimento da participação popular”. (DANIEL, 1988, p. 6). Para ele, contudo, no estágio atual a população ainda era desprovida "da necessária experiência acumulada" na condução de conselhos populares, sendo importante pensar a intervenção do poder político local, que "tem condições de favorecer a participação dos movimentos sociais". (DANIEL, 1988, p. 1).

Dowbor (1988, p. 16), entendendo não haver modelo para a organização da participação comunitária, sugeria que uma variável a ser observada seria "o nível de conscientização já atingido pela população". Para Dowbor (1988, p. 20), "trata-se, sem dúvida, de um problema de maturidade política: somos um país sem cultura participativa e a transformação do nível de consciência é lenta". Gadotti (1988, p. 15), por sua vez, entendia que "só uma sólida formação política evitará reinvindicações corporativistas". Já Silva (1988, p. 32), acreditava que "é no município que se forma o cidadão". Por fim, Scheibel e Carnevale (1988, p. 120) pontuavam como primordial para o sucesso do municipalismo educacional o "efetivo preparo da comunidade para a participação, a fim de se diminuírem os riscos de manipulação por grupos político-partidários dominantes".

Se, por um lado, havia a crença de que os movimentos sociais de base comunitárias eram uma expressão autêntica e por vezes espontânea do espírito popular, por outro lado, entendia-se ser preciso um esforço de formação política da população, sendo a municipalização do EF instrumento de aperfeiçoamento dessa ainda frágil democracia.

\section{Considerações finais}

A ideia de municipalizar e educação básica para aperfeiçoar a democracia, comum ao imaginário social pautado num marxismo eclético e naquele que volta seu olhar aos EUA, demonstra que o imaginário social aqui analisado não é compartimentado. $O$ texto foi dividido em dois subtítulos - o imaginário social da democracia norte-americana e o da nova esquerda - por uma questão de clareza na exposição dos argumentos. Contudo, na imaginação social da década de 1980 - uma imaginação criativa e não mera cópia de modelos exógenos - tudo o que foi analisado nos dois subtítulos poderia se fundir. Darcy Ribeiro implementou, com os Cieps, uma experiência popular de esquerda ou, por conta da influência de Anísio Teixeira, uma experiência liberal? Gadotti (1992, p. 31), notadamente um pensador marxista, cita como exemplos de autonomia escolar no Brasil tanto a EscolaParque de Anísio Teixeira, como os Cieps de Darcy Ribeiro. São referências a experiências liberais ou populares de esquerda?

É a fluidez desse imaginário social que o tornou tão forte. O imaginário social de que a municipalização da educação básica seria capaz de aperfeiçoar a democracia era fluido o bastante para influenciar transformações históricas oriundas de grupos de 
diferentes tonalidades ideológicas, tanto liberais como da nova esquerda. Na década de 1990 a lógica neoliberal e gerencial torna-se hegemônica para justificar o empreendimento de políticas públicas municipalizadoras do EF. Contudo, não se pode desprezar a base tanto constitucional como imaginária - que havia sedimentado este processo.

\section{Referências}

ABRUCIO, Fernando Luiz. Os Barões da federação: os governadores e a redemocratização brasileira. São Paulo: Hucitec, 1998.

ALBUQUERQUE, Francisco Carlos Araújo. Estado e municipalização do ensino no Ceará: entre o regime de colaboração e a lógica do ajuste estrutural. $\mathbf{O}$ público e o privado, Fortaleza, Uece, n. 5, p. 43-59, jan./jun. 2005.

ANDRADE, Edson Francisco de. Surgimento e consolidação do Estado federativo no Brasil: implicações na gestão da educação. Revista Brasileira de História da Educação. Campinas/SP, v. 13, n. 1 (31), p. 227-253, jan./abr. 2013.

ARAÚJO, Gilda Cardoso de. Constituição, federação e propostas para o novo Plano Nacional de Educação: análise das propostas de organização nacional de educação brasileira a partir do regime de colaboração. Educação e Sociedade, Campinas, Unicamp, v. 31, n. 112, p. 749-768, jul./set. 2010.

Município, federação e educação: história das instituições e das ideias políticas no Brasil. 2005. 332 f. Tese (Doutorado em Educação) - Programa de Pós-Graduação em Educação, Universidade de São Paulo/USP, São Paulo, 2005.

ARAÚJO, José Carlos Souza et al. Educação, Imprensa e Sociedade no Triângulo Mineiro: a revista A Escola (1920-1921). História da Educação, Pelotas, Asphe/FaE/UFPel, v. 2, n. 3, p. 59-93, abr. 1998.

ARELARO, Lisete Regina Gomes. A municipalização do ensino: avaliação preliminar. Revista Educação Municipal, São Paulo, ano 1, n. 4, p. 67-76, mai. 1989.

ARRETCHE, Marta. Estado federativo e políticas sociais: determinantes da descentralização. Rio de Janeiro/São Paulo: Editora Revan/Fapesp, 2000.

. Mitos da Descentralização: Maior Democracia e eficiência nas Políticas Públicas?.

Revista Brasileira de Ciências Sociais, São Paulo, Anpocs, v. 11, n. 31, p. 44-66, 1996.

Relações federativas nas políticas sociais. Educação e Sociedade, Campinas, v. 23, n. 80 , p. 25-48, set. 2002.

AVELINO, Daniel Pitangueira de. Democracia em Conselhos: análise do processo decisório em conselhos nacionais. 2012. 156 f. Tese (Doutorado em Política Social) Programa de Pós-Graduação da Universidade de Brasília/UNB, Brasília, 2012.

AZEVEDO, Neroaldo Ponte de. A Undime e os desafios da educação municipal. Estudos Avançados, São Paulo, USP, v. 15, n. 42, p. 141-152, mai./ago. 2001.

BACZKO, Bronislaw. A imaginação social. In: LEACH, Edmund et al. AntrhroposHomem. Lisboa: Imprensa Nacional/Casa de Moeda, 1985.

BEDÊ, Waldyr Amaral. Editorial. Revista Educação Municipal, São Paulo, ano 1, n. 2, p. 3, set. 1988.

BRASIL. Assembleia Nacional Constituinte. Comissão da Família, da Educação, Cultura e Esportes, da Ciência e Tecnologia e da Comunicação. Subcomissão da Educação, Cultura e Esportes. Atas de Comissões. Brasília, DF, 1987. 570 f. 
Constituição da República Federativa do Brasil de 1988. Brasília, DF, 1988.

BUYSE, Omer. Methodos Americanos de Educação Geral e Technica. Bahia: Imprensa Official do Estado, 1927.

CALMON, João. João Calmon. Memória viva da educação brasileira. Brasília: Inep, 1991. CARVALHO, José Murilo de. A luta pela Re(s)pública. Jornal do Brasil, Rio de Janeiro, n. 149, 4 de setembro de 1988, p. 40.

. Federalismo e centralização no império brasileiro: história e argumento. In:

CARVALHO, José Murilo de. Pontos e bordados. Escritos de história e política. Belo Horizonte: Editora UFMG, 2005.

CASASSUS, Juan. A reforma educacional na América Latina no contexto da globalização. Cadernos de Pesquisa, Rio de Janeiro, Fundação Carlos Chagas, n. 114, p. 7-28, nov. 2001.

Descentralização e desconcentração educacional na América Latina:

Fundamentos e Crítica. Cadernos de Pesquisa, São Paulo, Fundação Carlos Chagas, n. 74, p. 11-19, ago. 1990.

CASTORIADIS, Cornelius. A instituição imaginária da sociedade. Rio de Janeiro: Paz e Terra, 1982.

CRUZ, Priscila; MONTEIRO, Luciano (Orgs.). Anuário Brasileiro da Educação Básica. São Paulo: Moderna, 2016.

DANIEL, Celso. Participação Popular. Revista Teoria e Debate, n. 2, p. 1-8, março de 1988. Disponível em: <http://www.teoriaedebate.org.br/index.php?q=materias/sociedade/ participacaopopular>. Acesso em: 22 jan. 2017.

DOIMO, Ana Maria. A vez e a voz do popular: movimentos sociais e participação política no Brasil pós-70. Rio de Janeiro: Relume-Dumará, 1995.

DOLHNIKOF, Miriam. O pacto imperial: origens do federalismo no Brasil do século XIX. São Paulo: Globo, 2005.

DOWBOR, Ladislau. Participação Comunitária. Revista Educação Municipal, São Paulo, ano 1, n. 1, p. 16-23, jun. 1988.

EDITORIAL. Revista Educação Municipal, São Paulo, ano 1, n. 1, p. 3, jun. 1988.

EDWARDS JR., D. Brent.; DEMATTHEWS, David E. Historical trends in educational decentralization in the United States and developing countries: A periodization and comparison in the post-WWII context. Education Policy Analysis Archives, Arizona State University, v. 22, n. 40, p. 1-39, jun. 2014.

ESPIG, Maria Janete. O Conceito de Imaginário: reflexões acerca de sua utilização pela História. Textura, Canoas, n. 9, p. 49-56, nov. 2003/jun. 2004.

FELDMAN, Ariel. Uma crítica às instituições representativas do período das regências (1832-1840). Almanack Braziliense, São Paulo, USP, n. 4, p. 65-82, nov. 2006.

FERNANDES, Florestan. A transição prolongada: o período pós-constitucional. São Paulo: Cortez, 1990.

2000 .

. Democracia e Socialismo. Crítica Marxista, Campinas, Unicamp, n. 11, p. 11-13,

FISCHEL, William A. Making the grade: the economic evolution of american school districts. Chicago: University of Chicago Press, 2009.

FLEURI, Reinaldo Matias. As diferentes Faces da Educação Popular. Revista Educação 
Municipal, São Paulo, ano 1, n. 2, p. 22-24, set. 1988.

FRANCO, Dalva de Souza. A gestão de Paulo Freire à frente da Secretaria Municipal de Educação de São Paulo (1989-1991) e suas consequências. Pró-Posições, Campinas, Unicamp, v. 25, n. 3 (75), p. 103-121, set./dez. 2014.

FREIRE, Paulo. Alfabetização e Cidadania. Educação Municipal, São Paulo, ano 1, n. 1, p. 6-15, jun. 1988.

GADOTTI, Moacir. A escola cidadã. São Paulo: Cortez, 1992.

. Escola pública popular. Revista Educação Municipal, São Paulo, ano 1, n. 2, p.

5-17, set. 1988.

GINZBURG, Carlo. O fio e os rastros. Verdadeiro, falso, fictício. São Paulo: Companhia das Letras, 2007.

GOMES, Candido Alberto da Costa. Relacionamento escola-comunidade na cidade do Rio de Janeiro. Cadernos de Pesquisa, São Paulo, Fundação Carlos Chagas, n. 35, p. 25-33, nov. 1980.

GRAMSCI, Antonio. Escritos políticos. Lisboa: Seara Nova, 1976.

GUIMARÃES, José Luiz. Desigualdades regionais na educação: a municipalização do ensino em São Paulo. São Paulo: Editora Unesp, 1995.

GUTIERRES, Dalva Valente Guimarães. A municipalização do ensino e a democratização educacional no município de Altamira (PA). Educação em Foco, Maringá, Universidade Estadual de Maringá, v. 15, p. 123-144, dez. 2012.

HABERMAS, Jürguen. Mudança estrutural da esfera pública. Investigações quanto a uma categoria da sociedade burguesa. Rio de Janeiro: Tempo Brasileiro, 1984.

HOWLEY, Craig; JOHNSON, Jerry; PETRIE, Jennifer. Consolidation of schools and districts: what the research says and what it means. Boulder, CO: National Education Policy Center, 2011.

JUNGMANN, Raul. Elementos para uma história da Undime. Revista Educação Municipal, São Paulo, ano 1, n. 1, p. 111-113, jun. 1988.

KARNAL, Leandro. História dos Estados Unidos: das origens ao século XXI. São Paulo: Contexto, 2010.

KOWARIK, Lúcio; SINGER, André. A experiência do Partido dos Trabalhadores na Prefeitura de São Paulo. Novos Estudos, São Paulo, Cebrap, n. 35, p. 195-216, mar. 1993.

KRAWCZYK, Nora Rut; VIEIRA, Vera Lúcia. Homogeneidade e Heterogeneidade nos Sistemas Educacionais: Argentina, Brasil, Chile e México. Cadernos de Pesquisa, Rio de Janeiro, Fundação Carlos Chagas, v. 36, n. 129, p. 673-704, set./dez. 2006.

LOVE, Joseph L. Federalismo y regionalismo en Brasil (1889-1937). In: CARMAGNANI, Marcello (Coord.). Federalismos latino-americanos: México, Brasil, Argentina. México: Fondo de Cultura Económica, 1993.

LUXEMBURGO, Rosa. A Revolução Russa. Petrópolis: Vozes, 1991.

. What does the Spartacus League want? Monthly review press, Berlin, 1971.

Disponível em: <https://www.marxists.org/archive/luxemburg/1918/12/14.htm>. Acesso em: 22 jan. 2017.

MARTINS, Angela Maria. Uma análise da municipalização do ensino no Estado de São Paulo. Cadernos de Pesquisa, Rio de Janeiro, Fundação Carlos Chagas, n. 120, p. 221- 
238, nov. 2003.

MARTINS, Paulo de Sena. Financiamento da educação básica por meio de fundos contábeis: estratégia política para a eqüidade, a autonomia e o regime de colaboração entre os entes Federados. 2009. Tese (Doutorado em Educação) - Universidade de Brasília, Brasília/DF, 2009.

MARTORANO, Luciano Cavini. Conselhismo e democracia. Crítica Marxista, Campinas: Unicamp, n. 28, p. 15-33, 2009.

MATTOS, Ilmar R. O tempo saquarema. A formação do Estado Imperial. São Paulo: Hucitec, 1990.

MELLO, Evaldo Cabral de. Rubro Veio: o imaginário da restauração pernambucana. Rio de Janeiro: Topbooks, 1997.

MELLO, Guiomar Namo de. A descentralização que vem do centro. Revista Educação Municipal, São Paulo, ano 1, n. 1, p. 46-60, jun. 1988.

MIGNOT, Ana Chrystina Venancio. Escolas na vitrine: Centros Integrados de Educação (1983-1987). Estudos Avançados, São Paulo, USP, v. 15, n. 42, p. 153-168, 2001.

MORDUCHOWICZ, Alejandro; ARANGO, Aída. Desenho institucional e articulação do federalismo educativo: experiências internacionais. In: OLIVEIRA, Romualdo Portela de; SANTANA, Wagner (Orgs.). Educação e federalismo no Brasil: combater as desigualdades, garantir a diversidade. Brasília: Unesco, 2010.

MUNICIPALIZAÇÃO DA EDUCAÇÃO BÁSICA TEM APOIO DE MACIEL. Jornal do Brasil, n. 9, 17 de abril de 1985, p. 6.

NATHANAEL, Paulo. Municipalização do ensino à mineira. In: O Estado de São Paulo, São Paulo, 12 de março de 1989, p. 52.

NEVES, Gleisi Heisler. Municipalização do ensino em nova perspectiva. 1992. $233 \mathrm{f}$. Dissertação (Mestrado em Educação) - Instituto de Estudos Avançados em Educação, Fundação Getúlio Vargas/FGV, Rio de Janeiro, 1992.

NOBRE, Marcos. Imobilismo em movimento. Da abertura democrática ao governo Dilma. São Paulo: Companhia das Letras, 2013.

PINTO, José Marcelino de Rezende. Uma análise do financiamento da educação no Estado da Califórnia, EUA. Cadernos de Pesquisa, São Paulo, Fundação Carlos Chagas, v. 35, n. 126, p. 699-722, set./dez. 2005.

RIBEIRO, Adelia Miglievich; SILVA, Leonardo Nolasco. Entrevista com Lia Faria. Simbiótica, Vitória, Universidade Federal do Espírito Santo, v. único, n. 6, p. 188-232, jun. 2014.

RIBEIRO, Darci. Mestre Anísio. Revista Educação Municipal, São Paulo, ano 1, n. 2, p. 57-64, jun. 1988.

ROMÃO, José Eustáquio. Municipalização do ensino: sim. Revista Educação Municipal, São Paulo, ano 1, n. 1, p. 60-72, jun. 1988.

ROSAR, Maria de Fátima Félix. A municipalização como estratégia de descentralização e de desconstrução do sistema educacional brasileiro. In: OLIVEIRA, Dalila (Org.). Gestão democrática da educação: desafios contemporâneos. Petrópolis, RJ: Vozes, 1997.

RÜSEN, Jörn. Aprendizagem histórica: fundamentos e paradigmas. Curitiba: W.A. Editores, 2012.

SANTOS, Boaventura de Sousa. O orçamento participativo em Porto Alegre: para uma 
democracia redistributiva. In: SOUSA, Boaventura de Sousa (Org.). Democratizar a democracia: os caminhos da democracia participativa. Rio de Janeiro: Civilização Brasileira, 2002. p. 455-560.

SANTOS, Boaventura de Sousa; AVRITZER, Leonardo. Para ampliar o cânone democrático. In: SOUSA, Boaventura de Sousa (Org.). Democratizar a democracia: os caminhos da democracia participativa. Rio de Janeiro: Civilização Brasileira, 2002. p. 3942.

SANTOS, Lincoln de Araújo. Entre a utopia e o labirinto: democracia e autoritarismo no pensamento educacional brasileiro dos anos 1980. 2010. 259 f. Tese (Doutorado em Educação) - Programa de Pós-Graduação em Políticas Públicas e Formação Humana, Universidade do Estado do Rio de Janeiro/Uerj, Rio de Janeiro, 2010.

SCHEILBEL, Maria F.; CARNEVALE, Rita M. S. Municipalização: por que tantas divergências? Revista Educação Municipal, São Paulo, ano 1, n. 2, p. 116-121, set. 1988.

SECRETÁRIA ACHA QUE CRIANÇA ESTUDAR OITO ANOS É FICÇÃO LEGAL. Jornal do Brasil, Rio de Janeiro, n. 13, 21 de abril de 1985, p. 17.

SILVA, Carlos Pereira de Carvalho e. Educação comunitária e descentralização. Revista Educação Municipal, São Paulo, ano 1, n. 2, p. 31-33, set. 1988.

SLEMIAN, Andréia. "Para além da boa ordem": o papel das constituições nas independências da América Latina (c. 1810-1826). Cadernos do CHDD, Brasília, Fundação Alexandre de Gusmão, ano IV, número especial, 2005.

SOUZA, Celina. Federalismo e descentralização na Constituição de 1988: processo decisório, conflitos e alianças. Dados: Revista de Ciências Sociais, Rio de Janeiro, Uerj, v. 44, n. 3, p. 513-560, 2001.

SOUZA, Donaldo Bello de; FARIA, Lia Ciomar Macedo de. Reforma do Estado, descentralização e municipalização do ensino no Brasil: a gestão política dos sistemas públicos de ensino pós-LDB 9.394/96. Ensaio: Avaliação e Políticas Públicas em Educação, Rio de Janeiro, Cesgranrio, v. 12, n. 45, p. 925-944, out./dez. 2004.

TEIXEIRA, Anísio. A municipalização do ensino primário. Revista Educação Municipal, São Paulo, ano 2, n. 5, p. 121-136, nov. 1989.

Em marcha para a democracia. À margem dos Estados Unidos. Rio de Janeiro: Editora Guanabara, s. d. [1934?]. Disponível em: <http://www.bvanisioteixeira.ufba.br/ livro3/chama_livro3.htm>. Acesso em: 22 jan. 2017.

. Aspectos americanos de educação. Salvador: Tip. de São Francisco, 1928.

TEIXEIRA, Elenaldo Celso. O local e global: limites e desafios da participação cidadã. São Paulo/Recife/Salvador: Cortez/Equip/Ufpa, 2002.

TOCQUEVILLE, Alexis de. Democracia na América: leis e costumes de certas leis e certos costumes políticos que foram naturalmente sugeridos aos americanos por seu estado social democrática. São Paulo: Martins Fontes, 1998.

TÓTORA, Silvana. A questão democrática em Florestan Fernandes. Lua Nova, São Paulo, Cedec, n. 48, p. 111-241, dez. 1999.

ÚLTIMA SEÇÃO. Revista Educação Municipal, São Paulo, ano 1, n. 1, p. 114-119, jun. 1988.

UMA PROPOSTA PARA A EDUCAÇÃO. Revista Educação Municipal, São Paulo, ano 1, n. 1, p. 88-95, jun. 1988. 
VEIGA, Cyntia Greive. A escola e a república: o estadual e o nacional nas políticas educacionais. Revista Brasileira de História da Educação, Campinas/SP, v. 11, n. 1 (25), p. 143-178, jan./abr. 2011.

WARDE, Miriam Jorge. Encantamentos e desencantamentos com a América: os Estados Unidos em escritas de Anísio Teixeira. Projeto História, São Paulo, n. 32, p. 171-189, jun. 2006.

YAMAMOTO, Osvaldo H. Educação e tradição marxista no Brasil. Comunicação \& Sociedade, São Paulo, Universidade Metodista de São Paulo, n. 10, p. 33-43, set./dez. 1997.

ARIEL FELDMAN é professor no Programa de Pós-Graduação em Educação em Cultura do Campus Universitário do Tocantins/Cametá, Universidade Federal do Pará, doutor em História Social pela Universidade de São Paulo.

Endereço: Campus Universitário do Tocantins/Cametá da UFPA, Travessa Padre Antônio Franco, 2617, 68400-000, Matinha, Cametá/PA, Brasil.

E-mail: aridu18@yahoo.com.br

MARINA FELDMAN é mestre em Educação pela Universidade Federal do Paraná e doutoranda em educação pela Rutgers University, com pesquisa em políticas educacionais. Endereço: 504 Braun Ave, Highland Park, 08904, New Jersey, USA.

E-mail: marinaafeldman@gmail.com

Recebido em 27 de março de 2017.

Aceito em 25 de julho de 2017. 